\title{
Detrimental effect of Bisphenol S in mouse germ cell cyst breakdown and primordial follicle assembly
}

\author{
Wen-Xiang Liu ${ }^{\text {a, b }}$, Farini Donatella ${ }^{c}$, Shao-Jing Tan ${ }^{\mathrm{a}, \mathrm{b}}$, Wei Ge ${ }^{\mathrm{b}}$, Jun-Jie Wang ${ }^{\mathrm{b}}$,

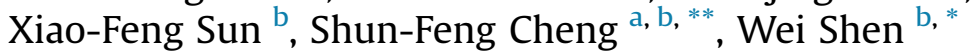 \\ ${ }^{a}$ College of Animal Science and Technology, Qingdao Agricultural University, Qingdao, 266109, China \\ ${ }^{\mathrm{b}}$ College of Life Sciences, Institute of Reproductive Sciences, Qingdao Agricultural University, Qingdao, 266109, China \\ ${ }^{\mathrm{c}}$ Department of Biomedicine and Prevention, University of Rome Tor Vergata, Rome, 00133, Italy
}

\section{H I G H L I G H T S}

- Bisphenol S (BPS) exposure results in abnormal germ cell cyst breakdown.

- BPS exposure activates the JNKs signaling through estrogen receptors.

- BPS exposure increase the proliferation of granulosa cells precursors.

\section{G R A P H I C A L A B S T R A C T}

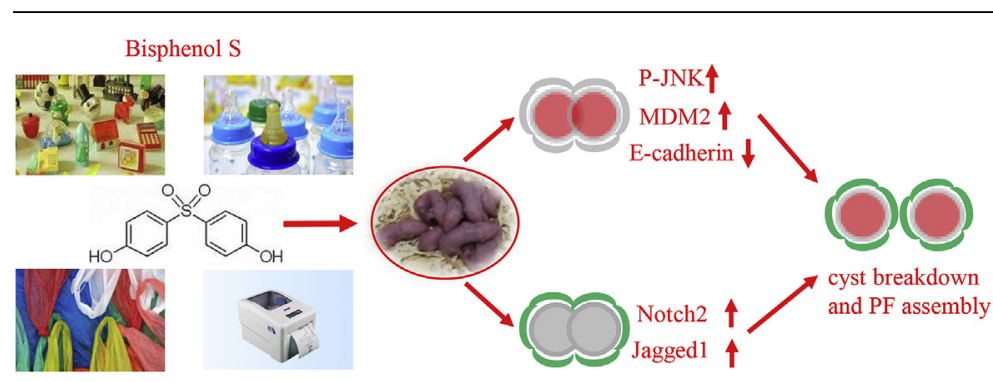

\begin{abstract}
A B S T R A C T
The female reproductive lifespan is largely determined by the size of primordial follicle pool, which is established in early life. Bisphenol S (BPS), frequently present in plastic products used in daily life, has been demonstrated as an exogenous estrogen-like endocrine disrupting chemical interfering with the endocrine and reproductive systems. However, the molecular mechanisms of its reproductive toxicity remain to be determined. In the present study, we focused on the effect of BPS on the early ovarian folliculogenesis of mice. Our in vivo experiments showed that the treatment with BPS at 2 and $10 \mu \mathrm{g} / \mathrm{kg}$ body weight/day for 3 days induced abnormal germ cell cyst breakdown and primordial follicle assembly in the mouse ovary, further affecting later ovarian differentiation and reducing oocyte quality. In addition, our in vitro study demonstrated that BPS could interact with estrogen receptors (ERs) to induce phosphorylation of JNKs, which is responsible for reducing oocyte adhesion in cysts. Meanwhile, BPS exposure up-regulated Notch signaling pathway to increase the proliferation of granulosa cells precursors. Our study provided new evidence for the adverse effects of BPS on female reproduction, especially after perinatal exposure, and elucidated how it works.
\end{abstract}

(C) 2020 Elsevier Ltd. All rights reserved.

\footnotetext{
* Corresponding author.

** Corresponding author. shenwei427@163.com (W. Shen).

E-mail addresses: sfcheng@qau.edu.cn (S.-F. Cheng), wshen@qau.edu.cn,

\section{Introduction}

Estrogen-like endocrine disrupting chemicals (estrogen-like EDCs) are a class of exogenous substances that interfere with the normal functioning of the endogenous hormonal axes (Ge et al., 2019; Yilmaz et al., 2019). Among them, Bisphenol A (BPA), a 
component of many plastic used in daily consumer products, is well known to possess an estrogen-mimicking action and it is considered potentially dangerous to health (Abraham and Chakraborty, 2019). Bisphenol S (BPS), a mainly substitute for BPA, is used as a monomer in synthetic polysulfone and epoxy resins, so it is frequently found in food packaging, baby plastic feeding bottle and toys, personal care products (Liao and Kannan, 2014), various papers (Liao et al., 2012b) and so on. It has been proved that BPS can enter the human body by food intake, air suction and skin absorption (Wu et al., 2018). Many studies have evaluated the physiological effects of BPS compared to BPA (Rochester and Bolden, 2015). It has been shown that BPS can induce endocrine disorders (Grandin et al., 2018) and have extensive effects on nervous systems (Kuruto-Niwa et al., 2005; Skledar et al., 2016). Of particular interest are studies concerning the effects related to the prenatal exposure to BPS that, for example, induce a precocious development of the mammary gland (Tucker et al., 2018) and affect female reproduction (Nevoral et al., 2018).

In female mice, from 10.5 days post-coitus (dpc) to $13 \mathrm{dpc}$, primordial germ cells (PGCs) migrate to the gonads (De Felici, 2016) and, as oogonia, form cysts by rapid mitosis and incomplete cytokinesis (Wang et al., 2017). At approximately 13.5 dpc, oogonia enter into meiosis prophase I (MPI) as oocytes, progress through the stage of the MPI, and are arrested at diplotene (Pepling, 2006). Within a few days after birth, germ cell cysts disappearance is concomitant with the formation of the primordial follicles (PFs) consisting of single oocytes surrounded by the pre-granulosa cells (Pepling and Spradling, 2001; Wang et al., 2017). From the beginning to the end of germ cell cyst breakdown, programmed apoptosis occurred in nearly two-thirds of the follicles (Pepling and Spradling, 2001).

Neonatal ovarian development is influenced by estrogens. Estradiol is able to inhibit cyst breakdown and PF assembly in ovary culture mimicking the maternal hormonal condition, thus preventing the premature PFs formation (Kezele and Skinner, 2003; Jefferson et al., 2006). In addition to binding nuclear receptors, estrogens activate a rapid non-genomic signaling (Simoncini and Genazzani, 2003). After binding to the ligand, ERs activate downstream signals (Barone et al., 2010), including the c-Jun N-terminal kinases (JNK) signaling that has an impact on the follicular formation. In fact, JNK is important for the germ cell cyst breakdown because it modulates the expression of E-cadherin in the junctions between oocytes (Niu et al., 2016).

The establishment of PFs pool requires the interaction between the oocyte and peripheral pro-granulosa cells and Notch signaling is one of the important mediators of this communication (Vanorny and Mayo, 2017). Indeed, JAG1 and JAG2 (the two ligands of Notch) in the oocyte signals through Notch2 in the pre-granulosa cells to facilitate the cyst breakdown and assembly of PF (Trombly et al., 2009; Guo et al., 2012).

In this paper, using in vivo and in vitro experimental approaches, we found that perinatal exposure to relatively low concentrations of BPS impaired primordial folliculogenesis and negatively influenced oocyte quality and the subsequent follicle development.

\section{Materials and methods}

\subsection{Animal and ethics statement}

All CD-1 mice were purchased from Vital River Laboratory Animal Technology Co. Ltd (Beijing, China), and all experiments were approved by the Ethics Committee of Qingdao Agriculture University (QAU; Agreement No. 2019-024). The mice were housed at $23{ }^{\circ} \mathrm{C}, 50 \%$ humidity, light and dark cycle of half day (lights on at 7:30 h) room with free-supplied food and water. Male mice were mated with female mice at 5 PM. The presence of the vaginal plug was considered as $0.5 \mathrm{dpc}$ and the mice were usually born at 19.5 $\mathrm{dpc}$ and this time was regarded as 0 day post-partum (dpp).

\subsection{Intraperitoneal injection in newborn mice}

The stock solution of $1 \mathrm{M}$ Bisphenol S (Sigma, 103039-100G) was prepared in DMSO. BPS, diluted in normal saline solution, was used within the range of human exposure at 2 and $10 \mu \mathrm{g} / \mathrm{kg}$ body weight (bw)/day (Liao et al., 2012a). The female newborn mice were intraperitoneally injected for three days. After treatment, the ovaries were collected and cysts or primordial follicles were counted. The oocytes were marked by positive staining of germ cell specific protein MOUSE VASA HOMOLOG (MVH). A PF was described as an individual oocyte surrounded by a monolayer of pre-granulosa cells with flattened nuclei, and the aggregation of two or more germ cells was defined as cysts (Pepling, 2006).

\subsection{Ovary culture}

0 dpp ovaries were isolated and cultured as previously described (Wang et al., 2018). Briefly, after isolation, the ovaries were cultured on Millicell-PC membrane inserts (Millipore, PIHA01250, Medford, MA, USA) for 3 days. The culture medium was Dulbecco's Modified Eagle's Medium (DMEM)/F12 (Hyclone, SH30023.01B, Beijing, China) and $\alpha$-Minimum Essential Medium ( $\alpha$-MEM; Hyclone, SH30265.01B) (1:1) supplemented with $10 \%$ fetal bovine serum (FBS; Gibco, 10099-141, USA), $0.23 \mathrm{mmol} / \mathrm{L}$ sodium pyruvate, 1\% Penicillin-Streptomycin Solution (HyClone; SV30010). Ovarian tissue was incubated at $37{ }^{\circ} \mathrm{C}$ in a $5 \% \mathrm{CO} 2$ and half of the culture medium was replaced by fresh medium every two days. BPS was added to the cultures at $10-100 \mu \mathrm{M}$ according to previous studies (Macczak et al., 2017). The ER antagonist Tamoxifen stock solution ( $1 \mathrm{M}$ ) was prepared in 50\% ethanol (TAM, Solarbio, T9010) (Thewes et al., 2017). The JNK inhibitor SP600125 (Beyotime, S1876) was prepared in DMSO $(10 \mathrm{mg} / \mathrm{ml}$ ) (Niu et al., 2016). All the reagents were diluted to working concentrations using medium and used as indicated in the literature (Niu et al., 2016; Liu et al., 2019).

\subsection{Immunofluorescence (IF) and immunohistochemistry (IHC)}

As previously described (Liu et al., 2019), the ovaries were fixed in $4 \%$ paraformaldehyde (Solaibio, P1110, Beijing, China) overnight and serially sectioned at $5 \mu \mathrm{m}$ after paraffin embedding. After antigen retrieval procedure, the sections used for peroxidase detection were transferred in $3 \% \mathrm{H}_{2} \mathrm{O}_{2}$ for $10 \mathrm{~min}$, blocked with TBS supplemented with $3 \%$ BSA and $10 \%$ normal goat serum (BDT) for $45 \mathrm{~min}$ at room temperature, and finally incubated with the primary antibodies (Table S1) overnight at $4{ }^{\circ} \mathrm{C}$. After washing with TBST (TBS supplemented with $0.1 \%$ Tween-20), the slides used for IF were incubated with FITC- or Cy3-conjugated secondary antibodies for $45 \mathrm{~min}$ at $37^{\circ} \mathrm{C}$. The nuclei were stained with propidium iodide (PI) (Solaibio, P8080-10) or Hoechst 33,342. The slides used for IHC were incubated with biotin-labeled secondary antibodies for $45 \mathrm{~min}$ at $37{ }^{\circ} \mathrm{C}$, then stained with DAB peroxidase substrate and counterstained with hematoxylin. Oocytes in the cysts or into PFs were counted every five sections in a double-blind manner as indicated before with the Image-Pro Plus software 6.0 (Media Cybernetics, Rockville, MD, US).

\subsection{5-Eethynyl-2'-deoxyuridine (EDU) proliferation assay}

$10 \mu \mathrm{M}$ BPS exposes the ovaries for 3 days and thymidine analog, EdU ( $50 \mathrm{nM}$ ) was added to the culture medium $2 \mathrm{~h}$ before the collection. As previously described (Wang et al., 2018), the 
percentage of somatic cells in S-phase was scored using the CellLight EdU DNA cell proliferation kit (RiboBio, C10371-1, Guangzhou, China). Paraffin serial sections ( $5 \mu \mathrm{m})$ were incubated for MVH (Table S1) detection and the staining reaction mix was added to the slides for 30 min. Nuclei were visualized with Hoechst 33,342. EdUpositive somatic cells were scored every five sections in a doubleblind manner under a fluorescence microscope (BX43, Olympus).

\section{6. $R N A$ extraction and real-time $R T-q P C R$}

The total RNA from ovarian tissue was prepared using RNAprep pure MicroKit (Aidlab, RN07, Beijing, China) following the manufacturer's instructions. Reverse transcription was carried out using the TransScript ${ }^{\circledR}$ One-Step gDNA Removal Kit and cDNA Synthesis Kit (TransGen Biotech, AT311, Beijing, China). RT-qPCR was performed using a LightCycler 480 II instrument (Roche, Germany) and the SYBR ${ }^{\circledR}$ Premix Ex Taq ${ }^{\mathrm{TM}}$ II (Tli RNaseH Plus) (TaKaRa, RR820A, Dalian, China) according to the manufacturer's instructions. The primers are listed in Table S2 and each reactions were repeated least in triplicate. Relative mRNA expression levels were analyzed by the $2^{(-\Delta \Delta \mathrm{Ct})}$ method and normalized based on Gapdh.

\subsection{Western blot analysis}

Protein lysates from ovaries were prepared using $6 \mu \mathrm{L} /$ ovaries of RIPA solution (Beyotime, P0013C). After separation by SDS-PAGE, the proteins were transferred onto a polyvinylidene fluoride membrane (Millipore, ISEQ00010, USA). After being blocked in TBST buffer containing $10 \% \mathrm{BSA}$ at $4{ }^{\circ} \mathrm{C}$, the membrane was incubated with primary antibody (Table S1) overnight and with HRPconjugated secondary antibody for $2 \mathrm{~h}$ at RT the next day. Finally, the Omni-ECL ${ }^{\mathrm{TM}}$ Femto Light Chemiluminescence Kit (EpiZyme, SQ201) was used for chemiluminescence. The GAPDH was used as an internal control. Finally, AlphaView SA software (ProteinSimple, San Jose, USA) was used to determine the expression level of target proteins.

\subsection{Statistical analysis}

Each experiment was repeated at least three times with data expressed as the mean $\pm \mathrm{SD}$. The data were statistically tested by Student's $t$-test or one-way analysis of variance (ANOVA) followed by Tukey's test for multiple comparisons using GraphPad Prism analysis software (GraphPad Software, San Diego, CA). Student's ttest was used when only two data sets were compared. $\mathrm{P}<0.05$ was considered significantly different, while $\mathrm{P}<0.01$ was a highly significant difference.

\section{Results}

\subsection{BPS exposure results in abnormal germ cell cyst breakdown}

BPS, which is recently used to replace the potentially toxic BPA, has also been reported to have reproductive toxicity (Ullah et al., 2016). To investigate in more detail the effects of this estrogenlike EDCs on the ovary, we performed in vivo analysis in the mouse experimental model. Neonatal mice were daily intraperitoneally injected with 2 and $10 \mu \mathrm{g} / \mathrm{kg}$ BPS and the ovaries were collected after 3 days and scored for the number of oocytes in PF or into the cysts. As shown in Fig. 1A and B, in the BPS-treated group, the percentage of MVH-positive oocytes in PF was increased in a dose-dependent manner $(49.02 \pm 2.63 \%$ and $52.35 \pm 4.02 \%)$ compared to control group $(33.55 \pm 3.88 \%)$. In parallel, the percentage of oocytes in cysts were reduced (Fig. 1B and Table S3). Besides, BPS did not affect the total number of oocytes (Fig. 1C and
Table S3). The in vitro analysis of neonatal ovaries cultured with different concentrations of BPS gave similar results (Fig. 1D and E and Table S4), thus suggesting that BPS exposure could lead to abnormal germline cyst breakdown and PF assembly. The lowest concentration of BPS which caused abnormal germ cell cyst breakdown in vitro was $10 \mu \mathrm{M}$, so we chose this concentration for further in vitro studies.

\subsection{BPS accelerates germ cell cyst breakdown through the estrogen receptors}

It has been reported that BPS has estrogenic activity (Rochester and Bolden, 2015; Moreman et al., 2017; da Silva et al., 2019). To test if the detrimental effect of this estrogen-like EDCs on the ovary was due to this characteristic, we first analyzed the expression of estrogen receptor (ER) $-\alpha$, ER- $\beta$ in 0 dpp ovaries cultured for 3 days with $10 \mu \mathrm{M}$ BPS. The results showed in Fig. $2 \mathrm{~A}$ and B suggested that BPS treatment increased ER- $\alpha$ and ER- $\beta$ both at mRNA and protein levels.

To understand if the effect of BPS on the germ cell cyst breakdown was through ERs, we used the ER antagonist, Tam (Thewes et al., 2017), to block ER- $\alpha$ and ER- $\beta$ signaling. The ovaries were treated with $10 \mu \mathrm{M}$ BPS in the presence or not of $1 \mu \mathrm{M}$ Tam for 3 days and the PF assembly was analyzed after identification of $\mathrm{MVH}-$ positive oocytes (Fig. 2C). The percentage of oocytes in the PFs of the ovaries treated with $1 \mu \mathrm{M}$ Tam $(33.82 \pm 5.38 \%)$ alone was not induce significant change compared to the control group $(35.99 \pm 5.55 \%)$ (Fig. 2D and Table S5). When BPS and $1 \mu \mathrm{M}$ Tam were added to the ovary culture in combination, $1 \mu \mathrm{M}$ Tam blocked the promoting effect of BPS on germ cell cyst breakdown (Fig. 2D and Table S5). This effect was associated with a significant recovery of the oocytes that remained in the cysts (Fig. 2D and Table S5). Besides, there was no significant change in the total number of oocytes in different groups (Fig. 2E and Table S5). Taken together, these results indicated that BPS affects early follicular development through the ERs.

\subsection{BPS exposure activates the JNKs signaling}

Previous reports have demonstrated that the c-Jun N-terminal kinases (JNKs) signaling pathway is involved in the germline cyst breakdown and the formation of PF (Niu et al., 2016). In the sections of perinatal ovaries labeled with a JNK antibody, the localization of the kinase was evident in the cytoplasm of MVH-positive oocytes (Fig. 3A). Western blotting showed that BPS could promote the activation of JNK phosphorylation, while $1 \mu \mathrm{M}$ Tam could counteract the effect of BPS (Fig. 3B). In addition, $1 \mu \mathrm{M}$ Tam alone did not affect the phosphorylation level of JNK (Fig. 3B).

To investigate whether the effect of BPS on the early germ cell cyst breakdown was mediated by JNK signaling, we treated ovarian tissue for 3 days with BPS in the presence or not of $5 \mu \mathrm{M} \mathrm{SP600125,}$ an inhibitor of JNKs (Bennett et al., 2001). Consistent with previous studies (Niu et al., 2016), the percentage of oocytes in the PFs of the ovaries treated with $5 \mu \mathrm{M}$ SP600125 (24.52 $\pm 3.32 \%)$ alone was significantly reduced compared to the control group $(38.22 \pm 5.09 \%)$ (Fig. $3 \mathrm{C}$ and D, and Table S6). In the BPS plus $5 \mu \mathrm{M}$ SP600125 group, $5 \mu \mathrm{M}$ SP600125 blocked the promoting effect of BPS on germ cell cyst breakdown (Fig. 3D and Table S6). Besides, the total number of oocytes in different groups did not change significantly (Fig. 3E and Table S6).

In order to investigate whether BPS affects JNK signaling to accelerate germ cell cyst breakdown, We further explored the key protein expression level of JNK pathway components, MDM2 and E-cadherin (Lee et al., 2011; Niu et al., 2016), in the primordial follicle development. Ovaries of $0 \mathrm{dpp}$ were treated with BPS, alone 
A
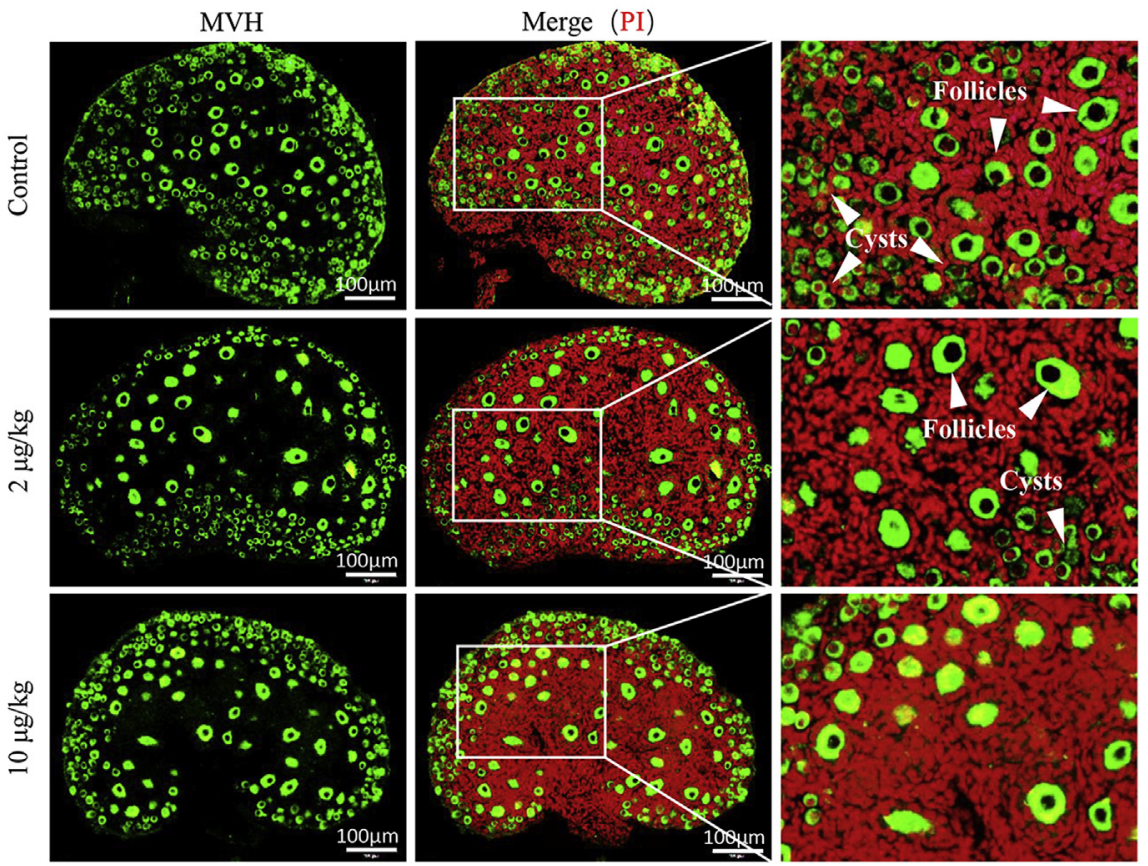

B

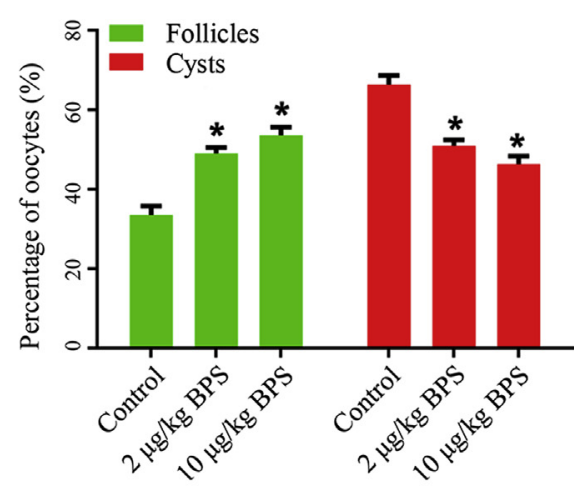

$\mathrm{D}$

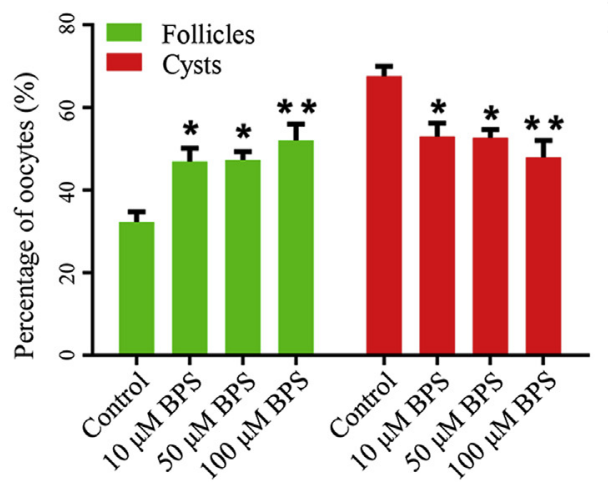

C

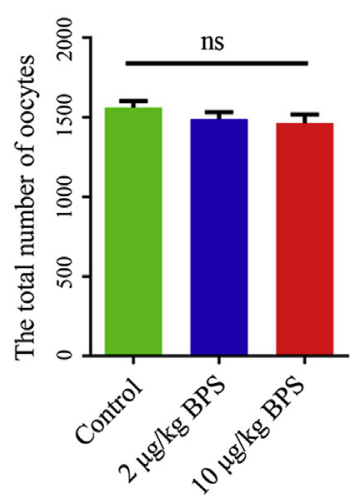

E

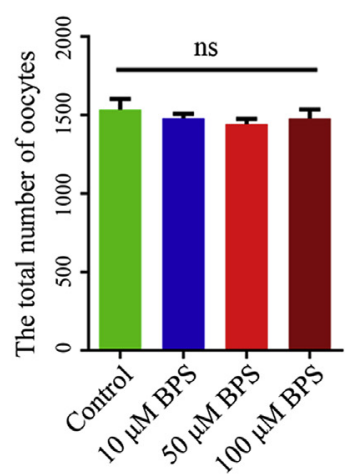

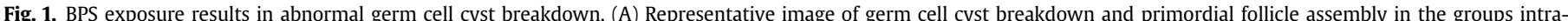

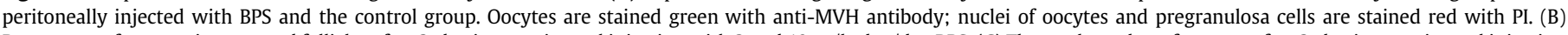

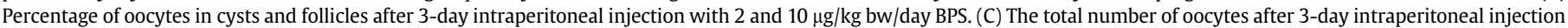

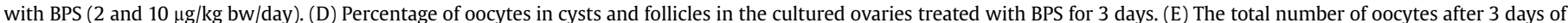

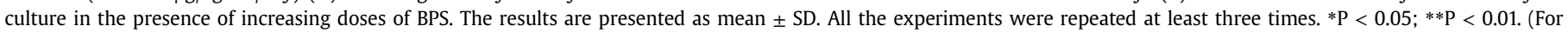
interpretation of the references to colour in this figure legend, the reader is referred to the Web version of this article.)

SP600125 or BPS plus SP600125 for 3 days. When BPS and SP600125 were added to the ovary culture, SP600125 was able to offset the effect of BPS on the JNK signaling pathway (Fig. 4). The IHC analysis showed MDM2 were expressed in the oocytes of each group (Fig. 4A). Moreover, Western blot results displayed that treatment with BPS increased the expression of MDM2, decreased the expression of E-cadherin, while adding SP600125 alone had the opposite effect (Fig. 4B and C). Interestingly, when both BPS and 
A

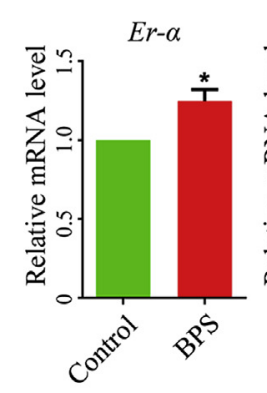

B

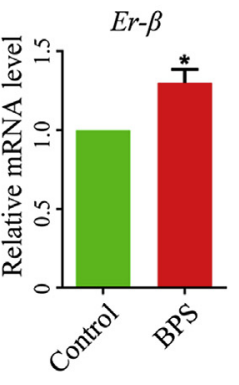

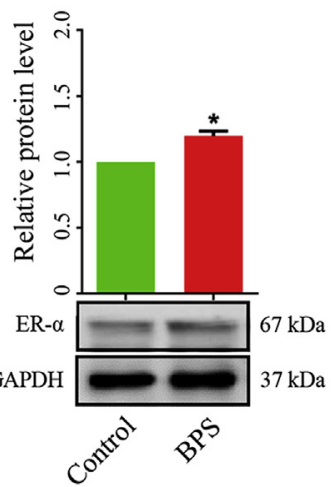

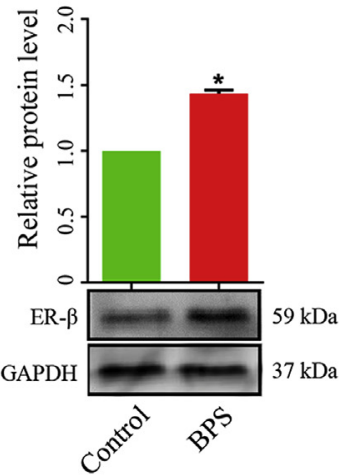

BPS+Tam

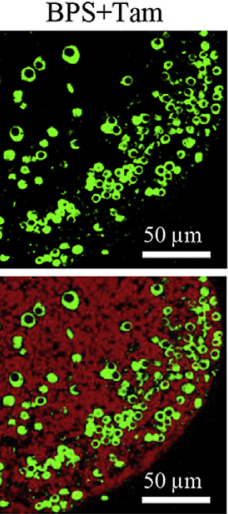

$\mathrm{D}$

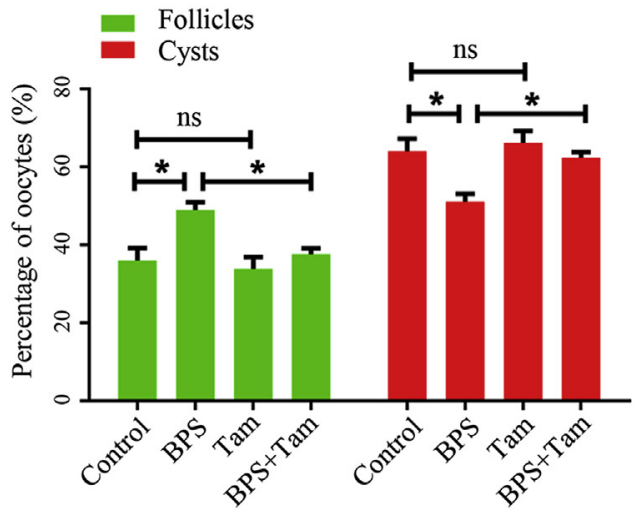

$\mathrm{E}$

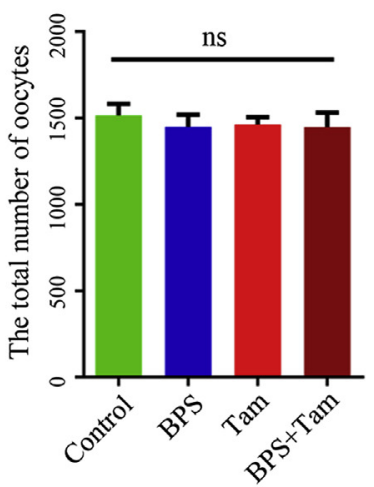

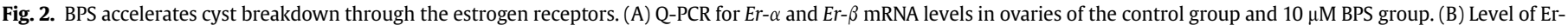

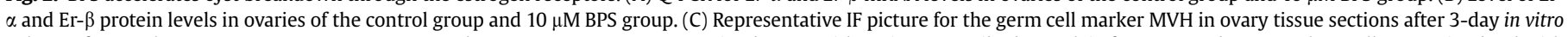

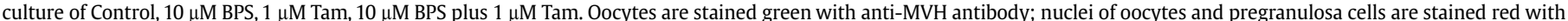

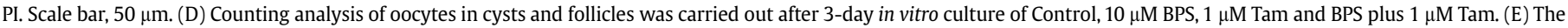

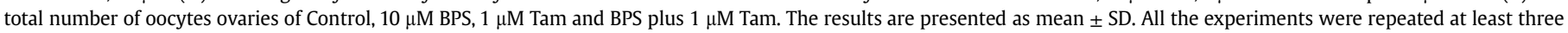
times. $* \mathrm{P}<0.05 ; * * \mathrm{P}<0.01$. (For interpretation of the references to colour in this figure legend, the reader is referred to the Web version of this article.)

SP600125 were present, SP600125 partially cancelled out the BPS effect (Fig. 4B and C). Our data implied that BPS could activate JNK signaling pathway in the ovary of perinatal mice, which results in accelerated primordial folliculogenesis.

\subsection{BPS exposure up-regulates notch signaling to increase the proliferation of granulosa cells precursors}

Since germline cyst breakdown and PF assembly involve granulosa cells (Mork et al., 2012), we wonder if BPS interferes with the proliferation of these cells. Newborn mice were intraperitoneally injected with 2 and $10 \mu \mathrm{g} / \mathrm{kg}$ BPS for 3 days and the proliferating cells in the ovarian tissue sections were identified by Ki67 immunodetection (Fig. 5A). BPS significantly promoted the proliferation of granulosa precursor cells in vivo in a dose-dependent manner (Control $=40.67 \pm 5.03 ; 2 \mu \mathrm{g} / \mathrm{kg}$ BPS $=106.7 \pm 8.62 ; 10 \mu \mathrm{g} / \mathrm{kg}$ $\mathrm{BPS}=127.7 \pm 14.64 ;$ Fig. $5 \mathrm{~A}$ and $\mathrm{B}$ ). This effect was confirmed when evaluating the number of proliferating cells labeled with EdU in the in vitro ovarian cultures treated with BPS (Control $=27.33 \pm 1.53$; $\mathrm{BPS}=46.33 \pm 3.51$; Fig. 5 C and D).

Previous studies have reported that Notch signaling in ovarian somatic cells governs the PF formation and mediates germ cell cyst breakdown (Trombly et al., 2009; Xu and Gridley, 2013). RT-qPCR and Western blot analysis showed that BPS significantly increased 
A
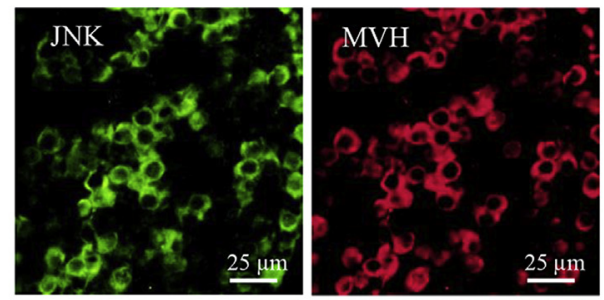

Hoechst

C
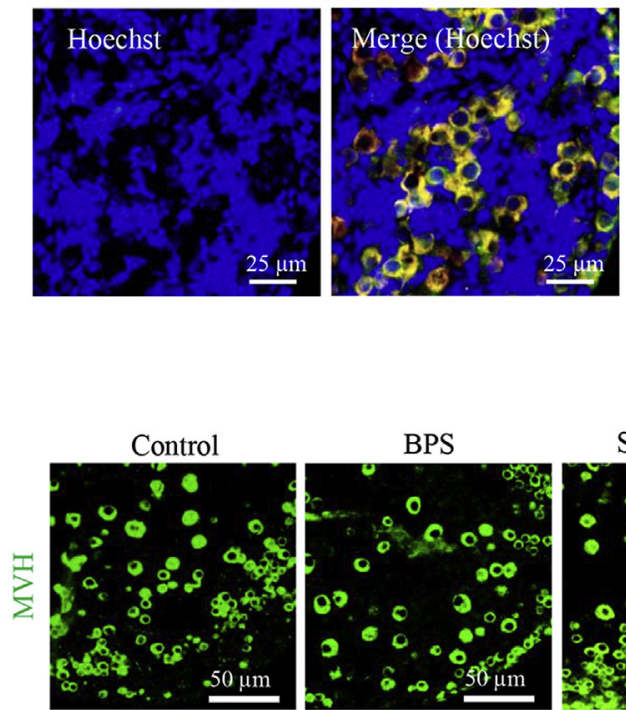

B
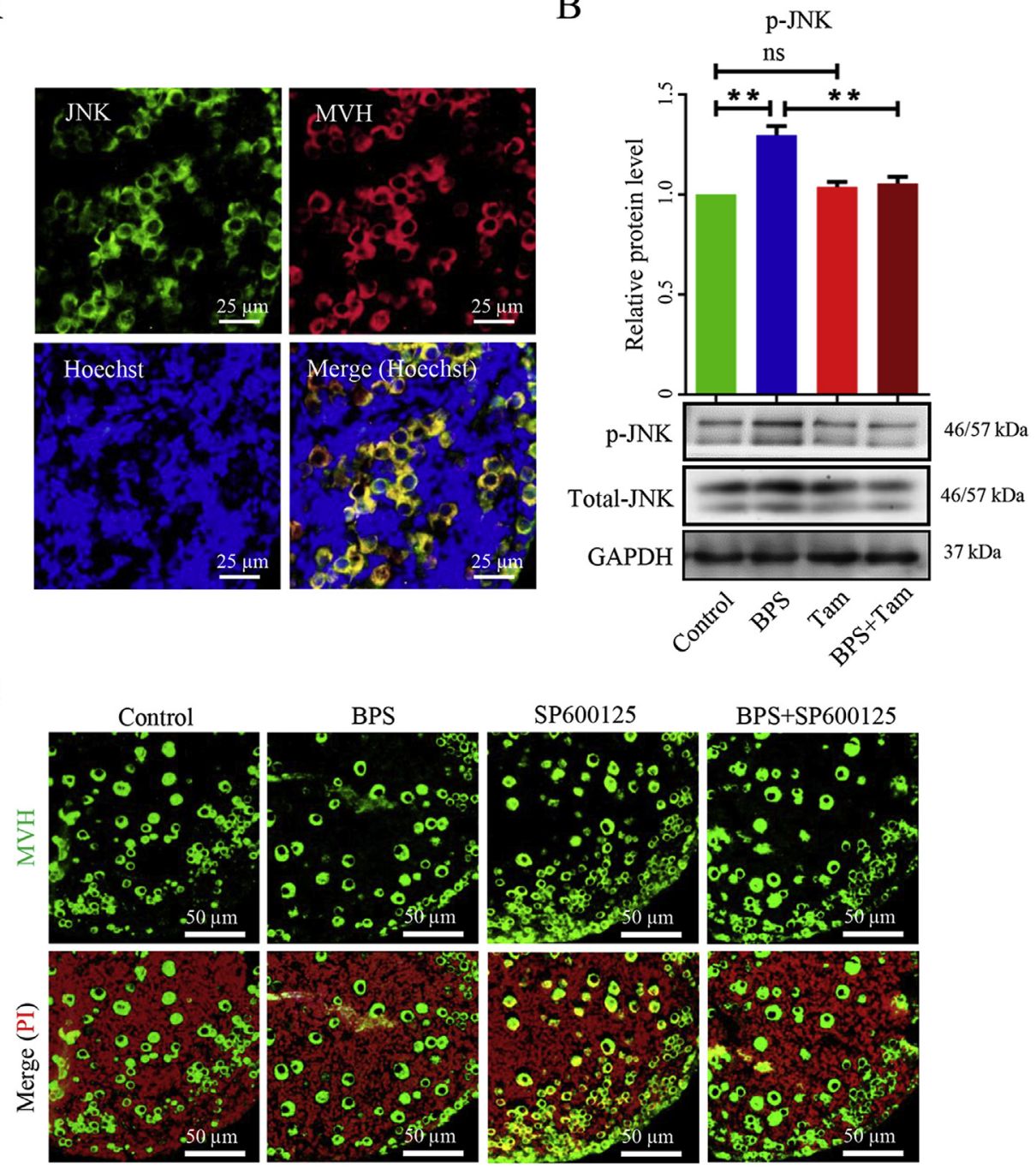

BPS+SP600125
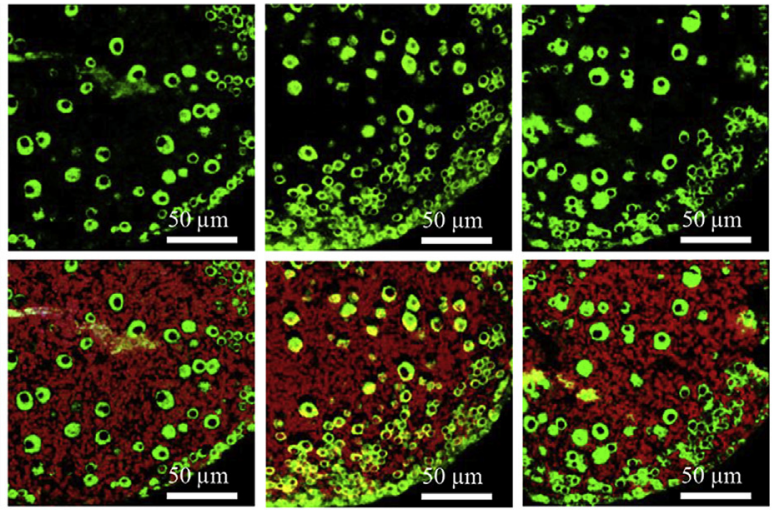

D

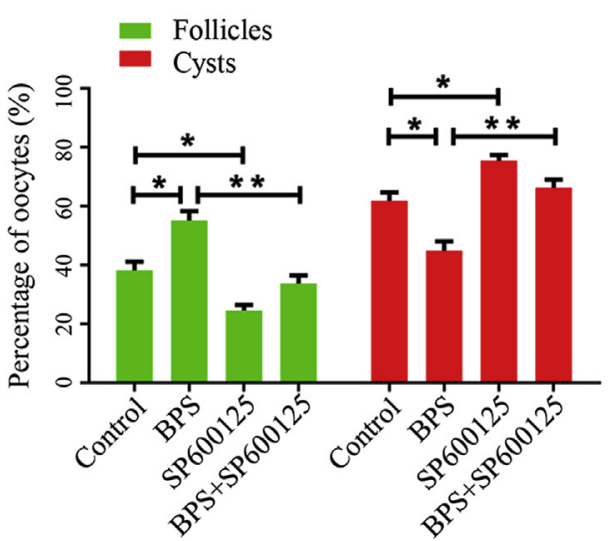

E

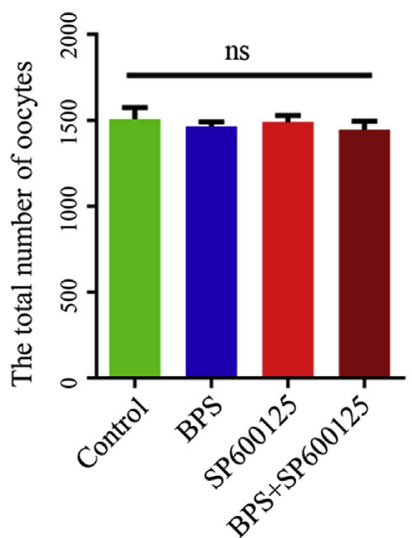

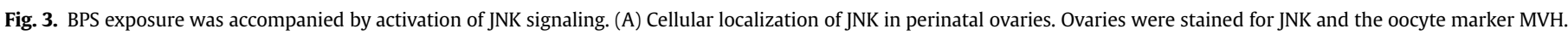

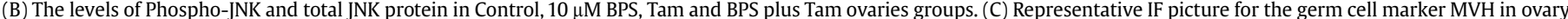

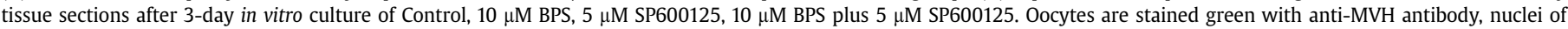

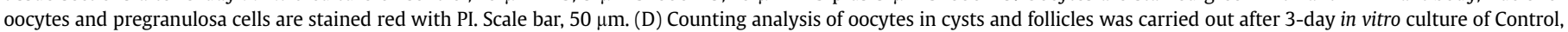

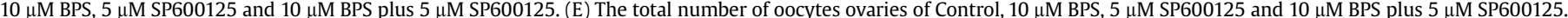

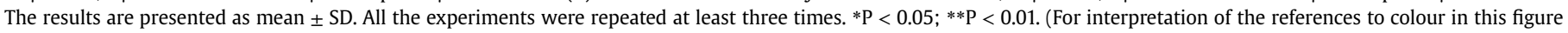
legend, the reader is referred to the Web version of this article.) 
A

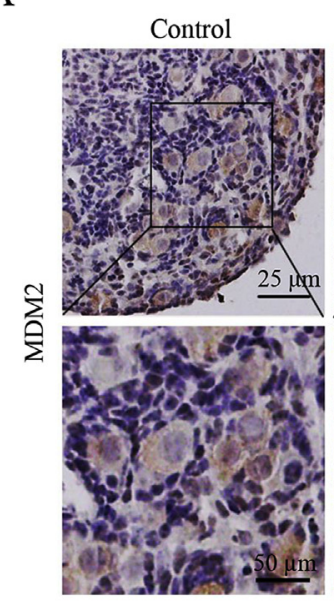

B

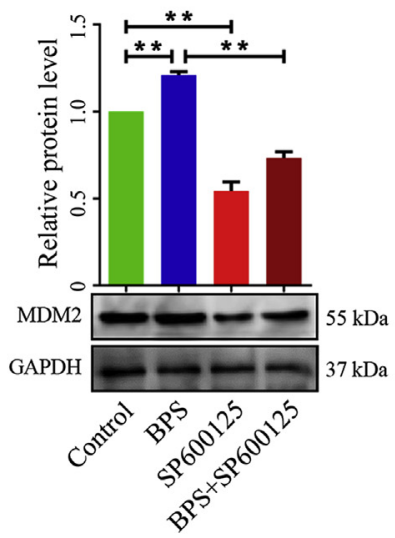

BPS

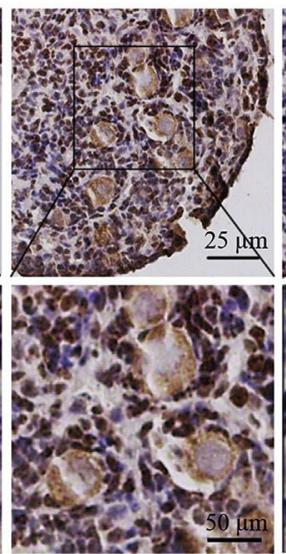

SP600125

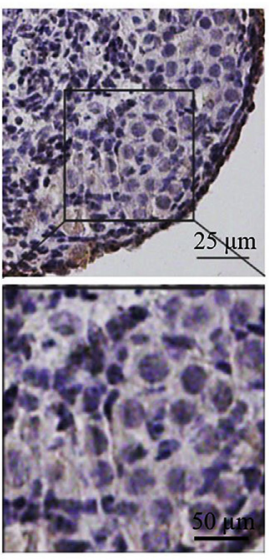

BPS + SP 600125

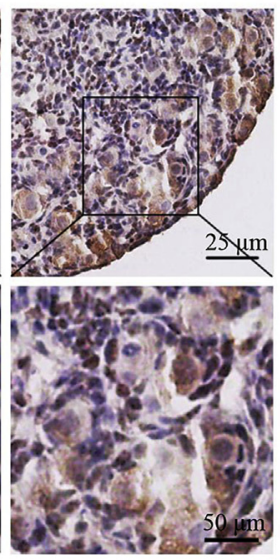

C

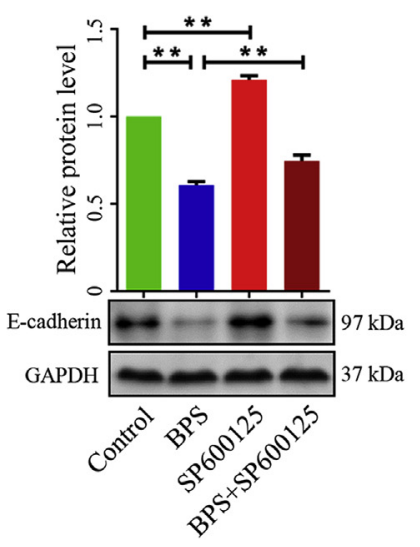

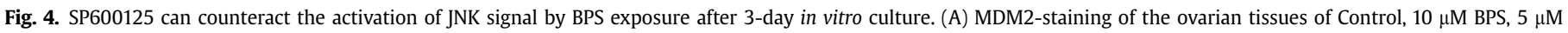

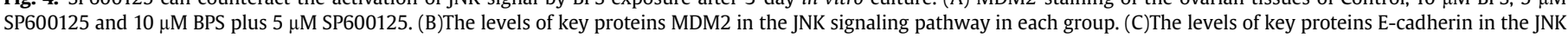
signaling pathway in each group. The results are presented as mean $\pm \mathrm{SD}$. All the experiments were repeated at least three times. $* \mathrm{P}<0.05$; $* * \mathrm{P}<0.01$.

the expression of Notch2 and Jagged 1 compared with the control group both at RNA and protein level (Fig. 5E and F), thus suggesting that BPS could promote the proliferation of granulosa cells through Notch pathway. In addition, we examined the expression of Connexin 43 (CX43), which is known to modulate granulosa cell proliferation and stratification to maintain normal follicular development (Ackert et al., 2001; Wright et al., 2001). The gene expression of $C \times 43$ in the ovary of the BPS group was significantly increased compared with the control group (Fig. 5G). Meanwhile, the examination of CX43 distribution in the labeled sections of cultured ovaries revealed the presence of numerous fine fluorescent puncta that increased with BPS exposure (Fig. $5 \mathrm{H}$ and I).

\subsection{Folliculogenesis is impaired after exposure to BPS in newborn} mice

We further examined the expression of quality related genes in oocyte after in vivo BPS treatment. To investigate whether the defects in the oogenesis process found in the neonatal mice ovary exposed to BPS damage the ovarian development at later stages, we checked the folliculogenesis at 21 days and the primordial follicle, primary follicle, secondary follicle and antral follicles were determined as described previously (Wang et al., 2018). At $21 \mathrm{dpp}$ in Fig. $6 \mathrm{~A}$ and $\mathrm{B}$, we scored a slight decrease in the oocyte number in BPS ovaries in comparison to control. In addition, no significant difference in the folliculogenesis between control and $2 \mu \mathrm{g} / \mathrm{kg}$ BPS ovaries was found (Fig. 6C and Table S7), while secondary follicles number was significantly lower in $10 \mu \mathrm{g} / \mathrm{kg}$ BPS-exposed neonatal mice ovaries in comparison to control (94.67 \pm 12.06 vs $148.3 \pm 17.21$ for the control group). There was also a significant decrease in the antral follicle number $(53.67 \pm 1.53$ vs $120.3 \pm 30.14$ for the control group) (Fig. 6C and Table S7). Noteworthy, primary follicles number was significantly increased in $10 \mu \mathrm{g} / \mathrm{kg}$ BPSexposed neonatal mice ovaries in comparison to control $(132 \pm 11.79$ vs $68.67 \pm 22.5$ for control group) (Fig. 6C and Table S7). We also examined the expression of oocyte-specific markers such as GDF9 (Dong et al., 1996) and BMP15 (Yan et al., 2001) during this period, and found that BPS exposure inhibited their expression at RNA and protein levels (Fig. 6D and E).

\section{Discussion}

The reproductive system is particularly susceptible to endocrine disruption. In particular, many data obtained in experimental animal models and in epidemiological analysis showed that the exposure to estrogen-like EDCs is very detrimental for the ovary (Vabre et al., 2017). BPS, a plastic compound present in a variety of daily-used objects, is a replacement for the estrogen-like EDCs BPA, but it has been shown that it is not without reproductive toxicity (Naderi et al., 2014; Qiu et al., 2016; Ullah et al., 2016; Grandin et al., 2018). Until now, published researches on the toxic effects of BPS are rather limited, especially on the reproductive system. The 
A
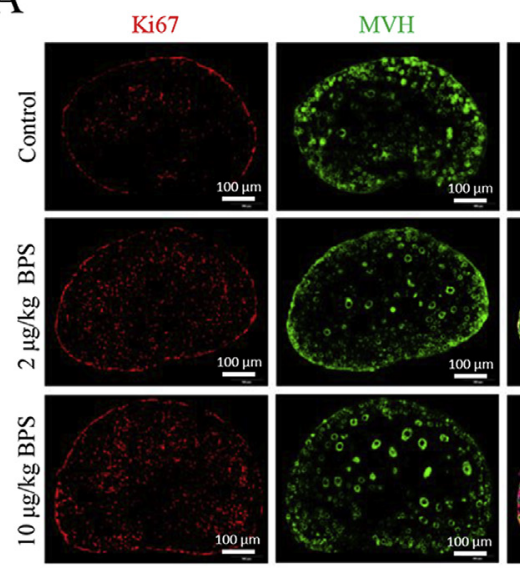

C
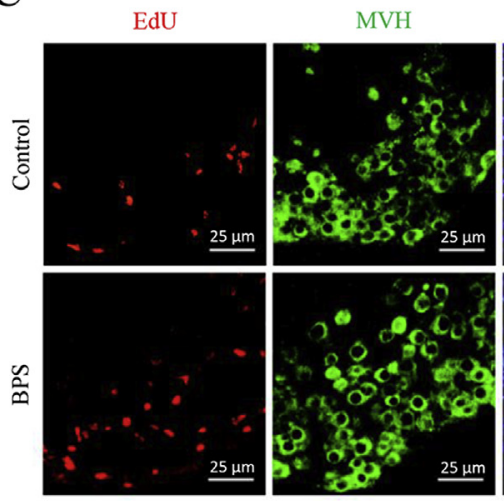

Merge(Hoechst)
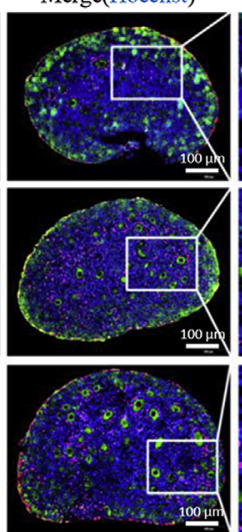

Hoechst

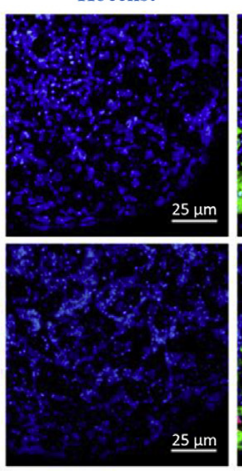

E
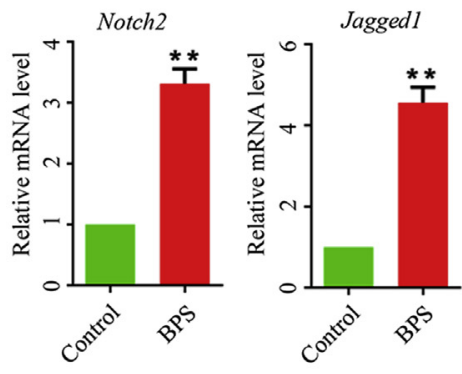

G

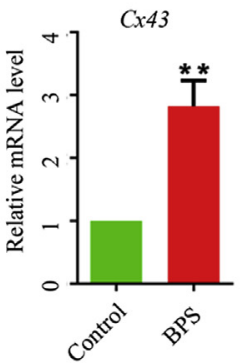

$\mathrm{H}$
F
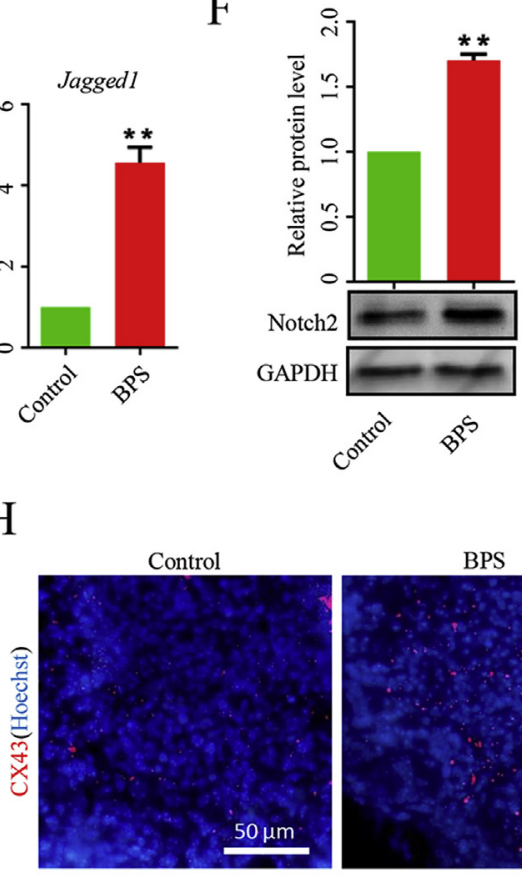

B
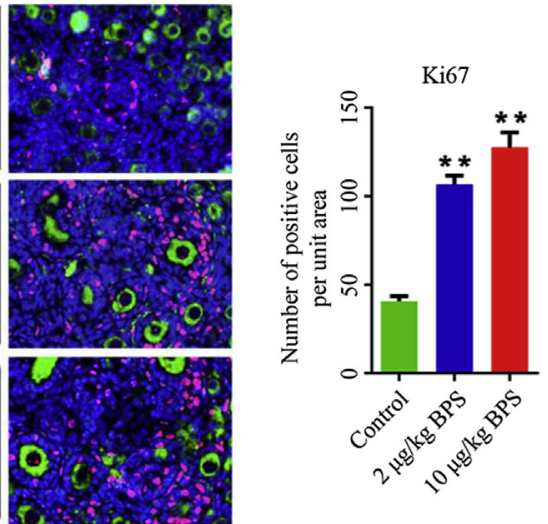

D

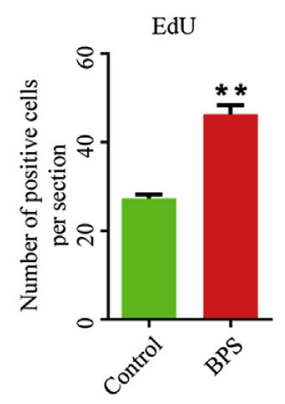

Merge
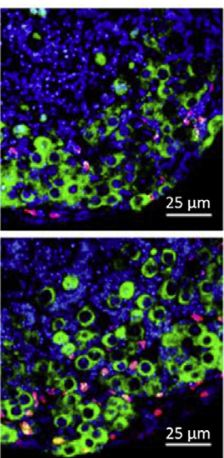
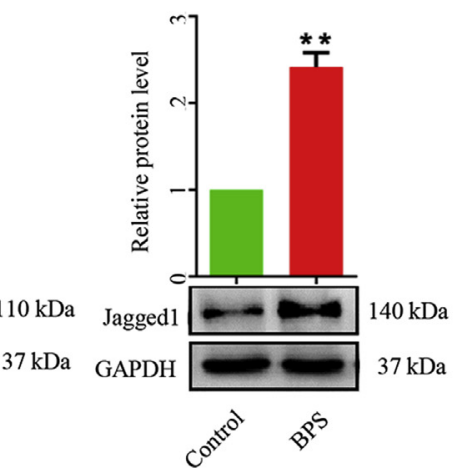

I

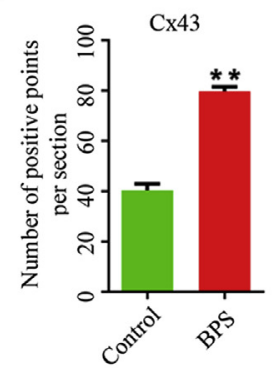

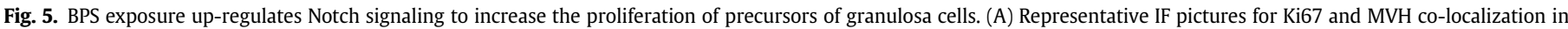

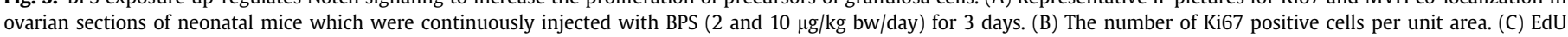

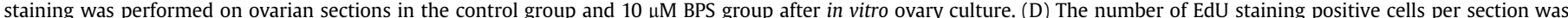

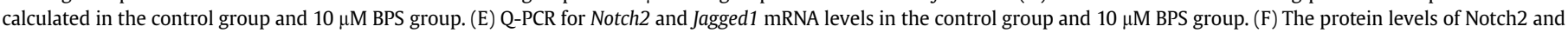

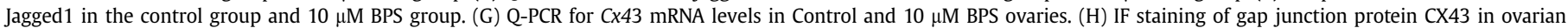

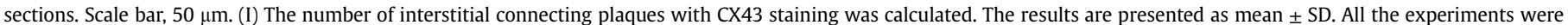
repeated at least three times. $* \mathrm{P}<0.05 ; * * \mathrm{P}<0.01$. 
A
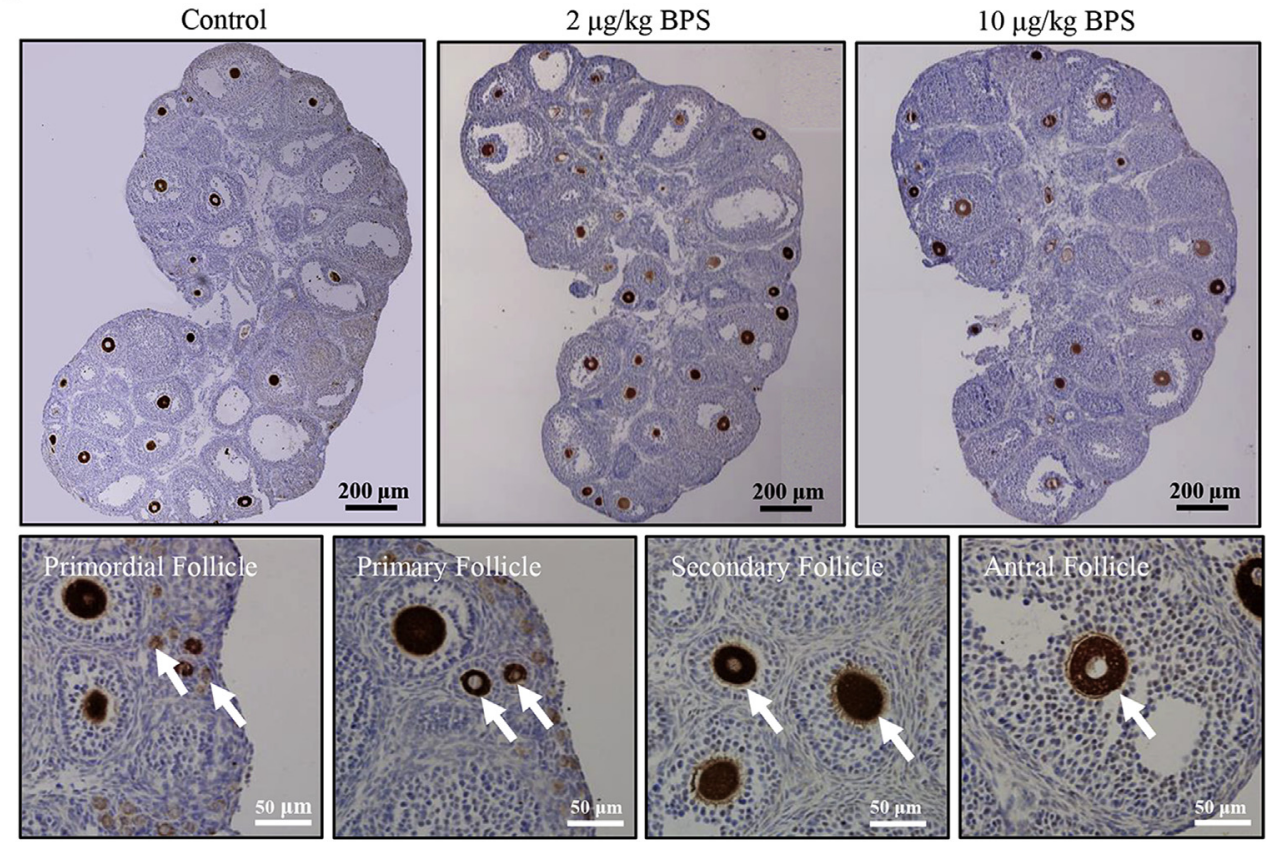

B

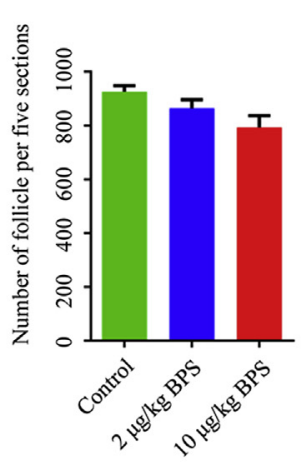

$\mathrm{D}$

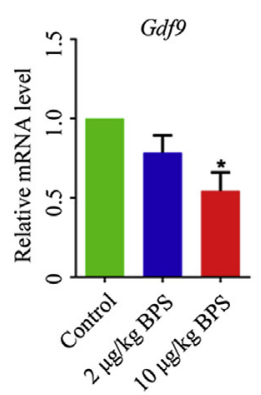

$\mathrm{C}$

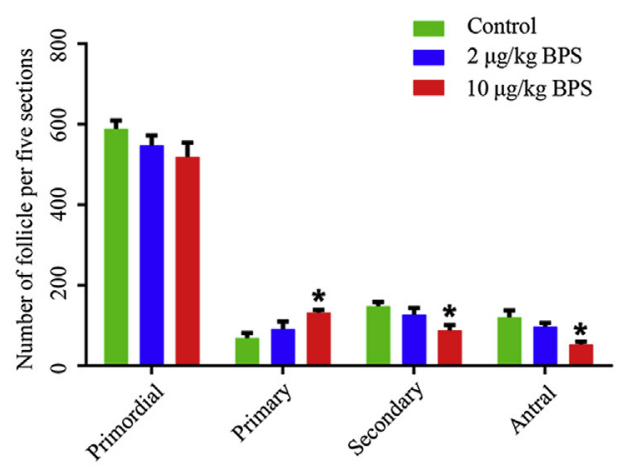

$\mathrm{E}$
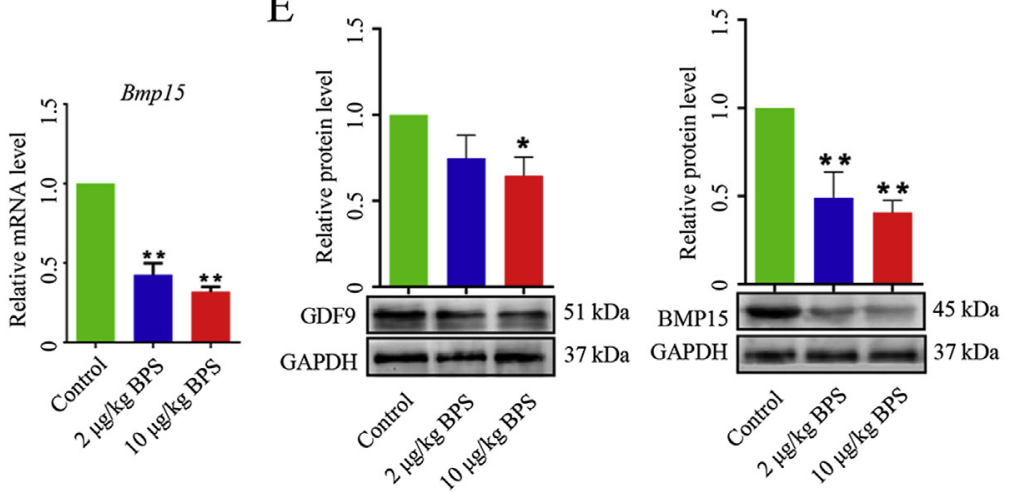

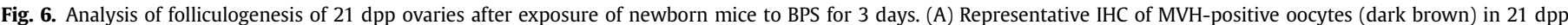

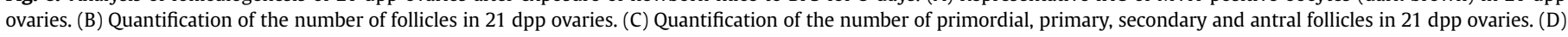

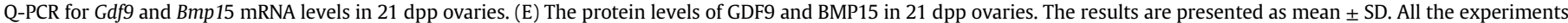

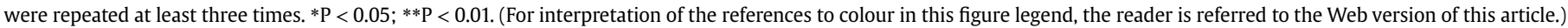

current study provides in vivo evidences that exposure of BPS accelerates the breakdown of oocyte cysts and the assembly of primordial follicles (Fig. 1A, B and 1C). We wonder the underlying molecular basis and mechanism regarding how BPS disrupts the process of primordial folliculogenesis. Some studies proved that the effect of estrogen-like EDCs, such as BPA and di(2-ethylhexyl) phthalate (DEHP), on cyst breakdown and primordial follicle assembly are mediated through ERs (Susiarjo et al., 2007; Mu et al., 2015). Similar results also in our paper, after BPS treatment, mRNA and protein levels of ER- $\alpha$ and ER- $\beta$ were increased (Fig. 2A 
and B). Meanwhile, our experiments indicated that the impact of BPS on PFs assembly and cyst breakdown can be reversed by Tam, a specific antagonist of ERs (Fig. 2C and D). These results further confirm the effect of BPS on cyst breakdown is mediated through the ERs.

Emerging evidence indicated that several signaling pathways, including transforming growth factor beta (TGF $\beta$ ) signaling, Notch signaling, phosphoinositide-3-kinase (PI3K) pathway, are important for the regulation of cyst breakdown and subsequently PF assembly (Tingen et al., 2009; Pepling, 2012; Wang et al., 2017). Here we just focus on the functional roles of JNK signaling during cyst breakdown and PF assembly after administrated with BPS, and found that treated ovaries with BPS could increase the levels of Phospho-JNK (Fig. 3B) and MDM2 (Fig. 4B), and decrease the protein expression level of E-cadherin (Fig. 4C). Moreover, we used SP600125, an inhibitor of JNKs, and the results showed SP600125 partially cancelled out the BPS effect (Fig. 3C, D, 4B and 4C). These data strongly suggest that BPS accelerates cyst breakdown and PFs formation by modulating JNK signaling pathway.

We found that the impact of BPS on PFs assembly and germ cell cyst breakdown can be reversed by the ER antagonist Tam (Fig. 2D and E). Tam is a nonsteroidal selective ER modulator which binds to ERs competitively with estrogens (Shagufta and Ahmad, 2018). Using in vitro model, we demonstrated that using $1 \mu \mathrm{M}$ or $5 \mu \mathrm{M}$ Tam alone had not obviously effect on germ cell cyst breakdown and PF formation (Fig. S1 and Table S5). Piasecka-Srader's experiments proved that in vitro treated rat ovaries even with $10 \mu \mathrm{M}$ Tam also had no effect on cell apoptosis and follicle loss (Piasecka-Srader et al., 2015). From these, we concluded that in vitro treated neonatal mouse ovaries with low dose Tam $(1 \mu \mathrm{M})$ may have no effect on the breakdown of oocyte cysts. But the underlying mechanism remains unclear and need to be further explored. On the other hands, evidence demonstrated that JNK signaling pathway determines primordial follicle formation in mice (Niu et al., 2016). Our experiment demonstrated that after treated with SP600125, an inhibitor of JNKs, MDM2 protein expression were significantly down-regulated and E-cadherin up-regulated (Fig. 4B and C), which in turn significantly inhibited PF formation (Fig. 3C and D). Similar results were reported by Niu et al. (2016), who proved that treatment of ovaries with $5 \mu \mathrm{M}$ SP600125 alone could significantly inhibit JNK phosphorylation and JNK signaling inhibition significantly suppresses the breakdown of germline cysts.

High levels of estrogens are known to prevent PFs assembly (Chen et al., 2007). However, in our in vivo and in vitro model of BPS action, we observed that BPS accelerates the breakdown of oocyte cysts and the assembly of PFs (Figs. 1 and 2). We postulated the reason may be relate to the dosage of administration. Nilsson et al. suggested that high concentrations estrogens inhibit follicle assembly while low concentrations promote assembly (Nilsson and Skinner, 2009). In previous estrogen-like EDCs research, such as BPA ( $5 \mathrm{mg} / \mathrm{kg}$ or $50 \mathrm{mg} / \mathrm{kg}$ ) (Karavan and Pepling, 2012) and DEHP (2.5-10 mg/kg) (Mu et al., 2015) exposure repress mouse germ cell cyst breakdown and PF assembly. In this paper, exposure of the newborn mice ovaries to BPS ( 2 and $10 \mu \mathrm{g} / \mathrm{kg}$ ) produced the opposite result (Figs. 1 and 2). The concentration of BPS used in this paper are much below the appropriate cutoff doses of chemicals in blood concentrations $(100-400 \mu \mathrm{g} / \mathrm{kg}$ ) and thus could be defined as 'low' (Taylor et al., 2011; Vandenberg, 2014). In addition, Do et al. (2012) and Lagarde et al. (2015) demonstrated that experimental studies investigating the effects of estrogen-like EDCs frequently identify potential non-monotonic dose-response relationships. Therefore, in the risk assessment of these substances, like BPS (da Silva et al., 2019) and BPA (Badding et al., 2019), da Silva et al. and Badding et al. suggested that simple monotone extrapolation from high to low dose is unreasonable.
In this paper, we presumed that prenatal ovarian exposure to BPS has long-term consequences. In fact, we found that the expressions of oocyte-specific genes, GDF9 and BMP15 are inhibited, thus indicating that BPS exposure reduced oocyte quality. Dong's experiment proved that female mice with insufficient GDF-9 expression could formed primordial and primary follicles, but there is a block in follicular development beyond the primary onelayer follicle stage which leads to infertility (Dong et al., 1996). From then on, plentiful studies have demonstrated the important role of GDF-9 in early follicle growth and differentiation (Hayashi et al., 1999; Hreinsson et al., 2002; Kobayashi et al., 2009). Moreover, increasing evidences have shown a synergistic relationship between GDF-9 and BMP-15 as GDF-9/BMP-15 heterodimers act as potent regulators regulate ovarian function, particularly in improveing oocyte quality (Su et al., 2008; Peng et al., 2013; Sanfins et al., 2018). In reality, BMP15 mutations have been associated with primary ovarian insufficiency (POI) and infertility phenotype (Galloway et al., 2000; Chand et al., 2006). Our results showed that BPS also adversely affected late-follicular development, particularly blocking the differentiation of primary follicles into secondary/ antral follicles, which may be related to the insufficient expression of GDF9 and BMP15.

In conclusion, our study shows that perinatal BPS ovarian exposure induces abnormal germ cell cyst breakdown. BPS probably affects not only the establishment of ovarian reserve but also late ovarian differentiation. To date, researches concering the toxic effects of BPS on the reproductive system rather limited, and the detailed mechanism of its influence on the female reproductive system development remains unclear and needs to be further explored.

\section{Author contributions}

Liu W.X. and Tan S.J. conducted the animal experiments; Liu W.X., Sun X.F. and Tan S.J. analyzed data; Donatella F., Ge W. and Wang J.J. wrote the manuscript; Cheng S.F. and Shen W. designed the manuscript. All authors revised the manuscript and approved the final manuscript.

\section{Declaration of competing interest}

The authors declare that they have no known competing financial interests or personal relationships that could have appeared to influence the work reported in this paper.

\section{Acknowledgements}

This work was supported by National Natural Science Foundation of China (31672423), Shandong Province Key Research and Development Program (2019GSF107082) and Taishan Scholar Construction Foundation of Shandong Province (ts20190946).

\section{Appendix A. Supplementary data}

Supplementary data to this article can be found online at https://doi.org/10.1016/j.chemosphere.2020.128445.

\section{References}

Abraham, A., Chakraborty, P., 2019. A review on sources and health impacts of bisphenol A. Rev. Environ. Health.

Ackert, C.L., Gittens, J.E., O’Brien, M.J., Eppig, J.J., Kidder, G.M., 2001. Intercellular communication via connexin43 gap junctions is required for ovarian folliculogenesis in the mouse. Dev. Biol. 233, 258-270.

Badding, M.A., Barraj, L., Williams, A.L., Scrafford, C., Reiss, R., 2019. CLARITY-BPA Core Study: analysis for non-monotonic dose-responses and biological 
relevance. Food Chem. Toxicol. 131, 110554.

Barone, I., Brusco, L., Fuqua, S.A., 2010. Estrogen receptor mutations and changes in downstream gene expression and signaling. Clin. Canc. Res. 16, 2702-2708.

Bennett, B.L., Sasaki, D.T., Murray, B.W., O'Leary, E.C., Sakata, S.T., Xu, W., Leisten, J.C., Motiwala, A., Pierce, S., Satoh, Y., Bhagwat, S.S., Manning, A.M., Anderson, D.W., 2001. SP600125, an anthrapyrazolone inhibitor of Jun N-terminal kinase. Proc. Natl. Acad. Sci. U. S. A 98, 13681-13686.

Chand, A.L., Ponnampalam, A.P., Harris, S.E., Winship, I.M., Shelling, A.N., 2006. Mutational analysis of BMP15 and GDF9 as candidate genes for premature ovarian failure. Fertil. Steril. 86, 1009-1012.

Chen, Y., Jefferson, W.N., Newbold, R.R., Padilla-Banks, E., Pepling, M.E., 2007. Estradiol, progesterone, and genistein inhibit oocyte nest breakdown and primordial follicle assembly in the neonatal mouse ovary in vitro and in vivo. Endocrinology 148, 3580-3590.

da Silva, B.S., Pietrobon, C.B., Bertasso, I.M., Lopes, B.P., Carvalho, J.C., PeixotoSilva, N., Santos, T.R., Claudio-Neto, S., Manhaes, A.C., Oliveira, E., de Moura, E.G., Lisboa, P.C., 2019. Short and long-term effects of bisphenol S (BPS) exposure during pregnancy and lactation on plasma lipids, hormones, and behavior in rats. Environ. Pollut. 250, 312-322.

De Felici, M., 2016. the formation and migration of primordial germ cells in mouse and man. Results probl. Cell Differ. 58, 23-46.

Do, R.P., Stahlhut, R.W., Ponzi, D., Vom Saal, F.S., Taylor, J.A., 2012. Non-monotonic dose effects of in utero exposure to di(2-ethylhexyl) phthalate (DEHP) on testicular and serum testosterone and anogenital distance in male mouse fetuses. Reprod. Toxicol. 34, 614-621.

Dong, J., Albertini, D.F., Nishimori, K., Kumar, T.R., Lu, N., Matzuk, M.M., 1996. Growth differentiation factor-9 is required during early ovarian folliculogenesis. Nature 383, 531-535.

Galloway, S.M., McNatty, K.P., Cambridge, L.M., Laitinen, M.P., Juengel, J.L., Jokiranta, T.S., McLaren, R.J., Luiro, K., Dodds, K.G., Montgomery, G.W., Beattie, A.E., Davis, G.H., Ritvos, O., 2000. Mutations in an oocyte-derived growth factor gene (BMP15) cause increased ovulation rate and infertility in a dosage-sensitive manner. Nat. Genet. 25, 279-283.

Ge, W., Li, L., Dyce, P.W., De Felici, M., Shen, W., 2019. Establishment and depletion of the ovarian reserve: physiology and impact of environmental chemicals. Cell. Mol. Life Sci. 76, 1729-1746.

Grandin, F.C., Lacroix, M.Z., Gayrard, V., Gauderat, G., Mila, H., Toutain, P.L., PicardHagen, N., 2018. Bisphenol S instead of Bisphenol A: toxicokinetic investigations in the ovine materno-feto-placental unit. Environ. Int. 120, 584-592.

Guo, M., Zhang, H., Bian, F., Li, G., Mu, X., Wen, J., Mao, G., Teng, Z., Xia, G., Zhang, M., 2012. P4 down-regulates Jagged 2 and Notch1 expression during primordial folliculogenesis. In: Biosci (Elite, Front (Ed.), 4, pp. 2631-2644.

Hayashi, M., McGee, E.A., Min, G., Klein, C., Rose, U.M., van Duin, M., Hsueh, A.J., 1999. Recombinant growth differentiation factor-9 (GDF-9) enhances growth and differentiation of cultured early ovarian follicles. Endocrinology 140, 1236-1244.

Hreinsson, J.G., Scott, J.E., Rasmussen, C., Swahn, M.L., Hsueh, A.J., Hovatta, O., 2002. Growth differentiation factor-9 promotes the growth, development, and survival of human ovarian follicles in organ culture. J. Clin. Endocrinol. Metab. 87, 316-321.

Jefferson, W., Newbold, R., Padilla-Banks, E., Pepling, M., 2006. Neonatal genistein treatment alters ovarian differentiation in the mouse: inhibition of oocyte nest breakdown and increased oocyte survival. Biol. Reprod. 74, 161-168.

Karavan, J.R., Pepling, M.E., 2012. Effects of estrogenic compounds on neonatal oocyte development. Reprod. Toxicol. 34, 51-56.

Kezele, P., Skinner, M.K., 2003. Regulation of ovarian primordial follicle assembly and development by estrogen and progesterone: endocrine model of follicle assembly. Endocrinology 144, 3329-3337.

Kobayashi, N., Orisaka, M., Cao, M., Kotsuji, F., Leader, A., Sakuragi, N., Tsang, B.K., 2009. Growth differentiation factor-9 mediates follicle-stimulating hormonethyroid hormone interaction in the regulation of rat preantral follicular development. Endocrinology 150, 5566-5574.

Kuruto-Niwa, R., Nozawa, R., Miyakoshi, T., Shiozawa, T., Terao, Y., 2005. Estrogenic activity of alkylphenols, bisphenol S, and their chlorinated derivatives using a GFP expression system. Environ. Toxicol. Pharmacol. 19, 121-130.

Lagarde, F., Beausoleil, C., Belcher, S.M., Belzunces, L.P., Emond, C., Guerbet, M., Rousselle, C., 2015. Non-monotonic dose-response relationships and endocrine disruptors: a qualitative method of assessment. Environ. Health 14, 13.

Lee, M.H., Padmashali, R., Koria, P., Andreadis, S.T., 2011. JNK regulates binding of alpha-catenin to adherens junctions and cell-cell adhesion. Faseb. J. 25, 613-623.

Liao, C., Kannan, K., 2014. A survey of alkylphenols, bisphenols, and triclosan in personal care products from China and the United States. Arch. Environ. Contam. Toxicol. 67, 50-59.

Liao, C., Liu, F., Alomirah, H., Loi, V.D., Mohd, M.A., Moon, H.B., Nakata, H., Kannan, K., 2012a. Bisphenol S in urine from the United States and seven Asian countries: occurrence and human exposures. Environ. Sci. Technol. 46, 6860-6866.

Liao, C., Liu, F., Moon, H.B., Yamashita, N., Yun, S., Kannan, K., 2012b. Bisphenol analogues in sediments from industrialized areas in the United States, Japan, and Korea: spatial and temporal distributions. Environ. Sci. Technol. 46, $11558-11565$.

Liu, J.C., Li, L., Yan, H.C., Zhang, T., Zhang, P., Sun, Z.Y., De Felici, M., Reiter, R.J., Shen, W., 2019. Identification of oxidative stress-related Xdh gene as a di(2ethylhexyl)phthalate (DEHP) target and the use of melatonin to alleviate the
DEHP-induced impairments in newborn mouse ovaries. J. Pineal Res. 67, e12577.

Macczak, A., Cyrkler, M., Bukowska, B., Michalowicz, J., 2017. Bisphenol A, bisphenol $\mathrm{S}$, bisphenol $\mathrm{F}$ and bisphenol $\mathrm{AF}$ induce different oxidative stress and damage in human red blood cells (in vitro study). Toxicol. In Vitro 41, 143-149.

Moreman, J., Lee, O., Trznadel, M., David, A., Kudoh, T., Tyler, C.R., 2017. Acute toxicity, teratogenic, and estrogenic effects of bisphenol A and its alternative replacements bisphenol S, bisphenol $\mathrm{F}$, and bisphenol AF in zebrafish embryolarvae. Environ. Sci. Technol. 51, 12796-12805.

Mork, L., Maatouk, D.M., McMahon, J.A., Guo, J.J., Zhang, P., McMahon, A.P., Capel, B. 2012. Temporal differences in granulosa cell specification in the ovary reflect distinct follicle fates in mice. Biol. Reprod. 86, 37.

Mu, X., Liao, X., Chen, X., Li, Y., Wang, M., Shen, C., Zhang, X., Wang, Y., Liu, X., He, J., 2015. DEHP exposure impairs mouse oocyte cyst breakdown and primordial follicle assembly through estrogen receptor-dependent and independent mechanisms. J. Hazard Mater. 298, 232-240.

Naderi, M., Wong, M.Y., Gholami, F., 2014. Developmental exposure of zebrafish (Danio rerio) to bisphenol-S impairs subsequent reproduction potential and hormonal balance in adults. Aquat. Toxicol. 148, 195-203.

Nevoral, J., Kolinko, Y., Moravec, J., Zalmanova, T., Hoskova, K., Prokesova, S., Klein, P., Ghaibour, K., Hosek, P., Stiavnicka, M., Rimnacova, H., Tonar, Z., Petr, J., Kralickova, M., 2018. Long-term exposure to very low doses of bisphenol S affects female reproduction. Reproduction 156, 47-57.

Nilsson, E.E., Skinner, M.K., 2009. Progesterone regulation of primordial follicle assembly in bovine fetal ovaries. Mol. Cell. Endocrinol. 313, 9-16.

Niu, W., Wang, Y., Wang, Z., Xin, Q., Wang, Y., Feng, L., Zhao, L., Wen, J., Zhang, H., Wang, C., Xia, G., 2016. JNK signaling regulates E-cadherin junctions in germline cysts and determines primordial follicle formation in mice. Development 143 , 1778-1787.

Peng, J., Li, Q. Wigglesworth, K., Rangarajan, A., Kattamuri, C., Peterson, R.T Eppig, J.J., Thompson, T.B., Matzuk, M.M., 2013. Growth differentiation factor 9: bone morphogenetic protein 15 heterodimers are potent regulators of ovarian functions. Proc. Natl. Acad. Sci. U. S. A. 110, E776-E785.

Pepling, M.E., 2006. From primordial germ cell to primordial follicle: mammalian female germ cell development. Genesis 44, 622-632.

Pepling, M.E., 2012. Follicular assembly: mechanisms of action. Reproduction 143 , 139-149.

Pepling, M.E., Spradling, A.C., 2001. Mouse ovarian germ cell cysts undergo programmed breakdown to form primordial follicles. Dev. Biol. 234, 339-351.

Piasecka-Srader, J., Blanco, F.F., Delman, D.H., Dixon, D.A., Geiser, J.L., Ciereszko, R.E., Petroff, B.K., 2015. Tamoxifen prevents apoptosis and follicle loss from cyclophosphamide in cultured rat ovaries. Biol. Reprod. 92, 132.

Qiu, W., Zhao, Y., Yang, M., Farajzadeh, M., Pan, C., Wayne, N.L., 2016. Actions of bisphenol A and bisphenol S on the reproductive neuroendocrine system during early development in zebrafish. Endocrinology 157, 636-647.

Rochester, J.R., Bolden, A.L., 2015. Bisphenol S and F: a systematic review and comparison of the hormonal activity of bisphenol A substitutes. Environ. Health Perspect. 123, 643-650.

Sanfins, A., Rodrigues, P., Albertini, D.F., 2018. GDF-9 and BMP-15 direct the follicle symphony. J. Assist. Reprod. Genet. 35, 1741-1750.

Shagufta, Ahmad, I., 2018. Tamoxifen a pioneering drug: an update on the therapeutic potential of tamoxifen derivatives. Eur. J. Med. Chem. 143, 515-531.

Simoncini, T., Genazzani, A.R., 2003. Non-genomic actions of sex steroid hormones. Eur. J. Endocrinol. 148, 281-292.

Skledar, D.G., Schmidt, J., Fic, A., Klopcic, I., Trontelj, J., Dolenc, M.S., Finel, M. Masic, L.P., 2016. Influence of metabolism on endocrine activities of bisphenol S. Chemosphere 157, 152-159.

Su, Y.Q., Sugiura, K., Wigglesworth, K., O’Brien, M.J., Affourtit, J.P., Pangas, S.A. Matzuk, M.M., Eppig, J.J., 2008. Oocyte regulation of metabolic cooperativity between mouse cumulus cells and oocytes: BMP15 and GDF9 control cholesterol biosynthesis in cumulus cells. Development 135, 111-121.

Susiarjo, M., Hassold, T.J., Freeman, E., Hunt, P.A., 2007. Bisphenol A exposure in utero disrupts early oogenesis in the mouse. PLoS Genet. 3, e5.

Taylor, J.A., Vom Saal, F.S., Welshons, W.V., Drury, B., Rottinghaus, G., Hunt, P.A. Toutain, P.L., Laffont, C.M., VandeVoort, C.A., 2011. Similarity of bisphenol A pharmacokinetics in rhesus monkeys and mice: relevance for human exposure. Environ. Health Perspect. 119, 422-430.

Thewes, V., Simon, R., Hlevnjak, M., Schlotter, M., Schroeter, P., Schmidt, K., Wu, Y. Anzeneder, T. Wang W. Windisch, P. Kirchgassner, M. Melling N., Kneisel, N., Buttner, R., Deuschle, U., Sinn, H.P., Schneeweiss, A., Heck, S., Kaulfuss, S., HessStumpp, H., Okun, J.G., Sauter, G., Lykkesfeldt, A.E., Zapatka, M., Radlwimmer, B., Lichter, P., Tonjes, M., 2017. The branched-chain amino acid transaminase 1 sustains growth of antiestrogen-resistant and ERalpha-negative breast cancer. Oncogene 36, 4124-4134.

Tingen, C., Kim, A., Woodruff, T.K., 2009. The primordial pool of follicles and nest breakdown in mammalian ovaries. Mol. Hum. Reprod. 15, 795-803.

Trombly, D.J., Woodruff, T.K., Mayo, K.E., 2009. Suppression of Notch signaling in the neonatal mouse ovary decreases primordial follicle formation. Endocrinology 150, 1014-1024.

Tucker, D.K., Hayes Bouknight, S., Brar, S.S., Kissling, G.E., Fenton, S.E., 2018. Evaluation of prenatal exposure to bisphenol analogues on development and longterm health of the mammary gland in female mice. Environ. Health perspect. 126, 087003.

Ullah, H., Jahan, S., Ain, Q.U., Shaheen, G., Ahsan, N., 2016. Effect of bisphenol S exposure on male reproductive system of rats: a histological and biochemical 
study. Chemosphere 152, 383-391.

Vabre, P., Gatimel, N., Moreau, J., Gayrard, V Picard-Hagen, N., Parinaud, J., Leandri, R.D., 2017. Environmental pollutants, a possible etiology for premature ovarian insufficiency: a narrative review of animal and human data. Environ. Health 16, 37.

Vandenberg, L.N., 2014. Low-dose effects of hormones and endocrine disruptors. Vitam. Horm. 94, 129-165.

Vanorny, D.A., Mayo, K.E., 2017. The role of Notch signaling in the mammalian ovary. Reproduction 153, R187-R204.

Wang, C., Zhou, B., Xia, G., 2017. Mechanisms controlling germline cyst breakdown and primordial follicle formation. Cell. Mol. Life Sci. 74, 2547-2566.

Wang, Y.F., Sun, X.F., Han, Z.L., Li, L., Ge, W., Zhao, Y., De Felici, M., Shen, W., Cheng, S.F., 2018. Protective effects of melatonin against nicotine-induced disorder of mouse early folliculogenesis. Aging (Albany NY) 10, 463-480.

Wright, C.S., Becker, D.L., Lin, J.S., Warner, A.E., Hardy, K., 2001. Stage-specific and differential expression of gap junctions in the mouse ovary: connexin-specific roles in follicular regulation. Reproduction 121, 77-88.

Wu, L.H., Zhang, X.M., Wang, F., Gao, C.J., Chen, D., Palumbo, J.R., Guo, Y., Zeng, E.Y., 2018. Occurrence of bisphenol S in the environment and implications for human exposure: a short review. Sci. Total Environ. 615, 87-98.

Xu, J., Gridley, T., 2013. Notch2 is required in somatic cells for breakdown of ovarian germ-cell nests and formation of primordial follicles. BMC Biol. 11, 13.

Yan, C., Wang, P., DeMayo, J., DeMayo, F.J., Elvin, J.A., Carino, C., Prasad, S.V. Skinner, S.S., Dunbar, B.S., Dube, J.L., Celeste, A.J., Matzuk, M.M., 2001. Synergistic roles of bone morphogenetic protein 15 and growth differentiation factor 9 in ovarian function. Mol. Endocrinol. 15, 854-866.

Yilmaz, B., Terekeci, H., Sandal, S., Kelestimur, F., 2019. Endocrine disrupting chemicals: exposure, effects on human health, mechanism of action, models for testing and strategies for prevention. Rev. Endocr. Metab. Disord. 21, 127-147. 